\title{
THE CINEMATIC ASPECTS OF ELECTROACOUSTIC MUSIC
}

\author{
By \\ Sarah Elizabeth Taylor
}

\begin{abstract}
A thesis
submitted to Massey University and Victoria

University of Wellington

in fulfillment of the requirements for the degree of

Master of Music

in Composition
\end{abstract}

New Zealand School of Music

2010 



\begin{abstract}
This portfolio explores 'the cinematic aspects of electroacoustic music' by way of three compositional contexts: acousmatic composition drawing on filmic resources, electroacoustic soundtracks for short films, and the narrative and imagic aspects of archival recordings. Additionally, a research report provides commentary on the aesthetic and methodological aspects of the portfolio.
\end{abstract}




\section{ACKNOWLEDGEMENTS}

I wish to acknowledge the following individuals and institutions for their assistance and support in completing this thesis:

Dr. Dugal McKinnon, my supervisor extraordinaire for his advice, patience, support and belief in me.

Michael Norris and Lissa Meridan, for their additional supervisory guidance and finely tuned ears.

The Lilburn Electroacoustic Music Studios and the ever-obliging technician Roy Carr, at the New Zealand School of Music.

The New Zealand Film Archive for their vast library of films through which to search, and to Sarah Davey for her liaison between myself and the filmmakers and for providing me with copies of the films with which to work.

Leon Narbey and Lissa Mitchell for their kind permission to use their creative and inspiring films.

Jacques Tati, for his inspired understanding of sound and cinema.

My loving family for lending their voices and ears over many years.

Finally, my amazing husband Daniel for his unwavering support and love, and without whom this would not have been possible. 


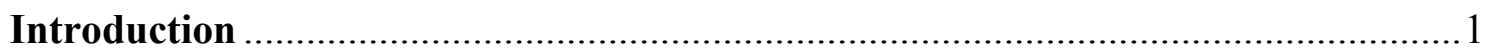

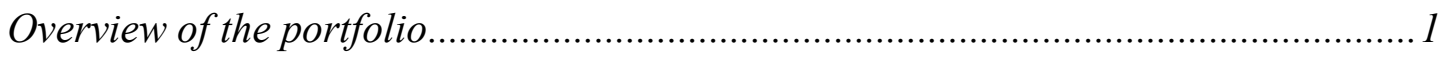

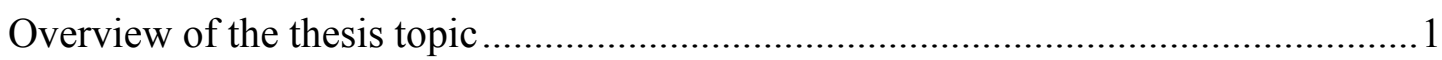

Aesthetic concerns, sonic materials and compositional techniques ....................................... 3

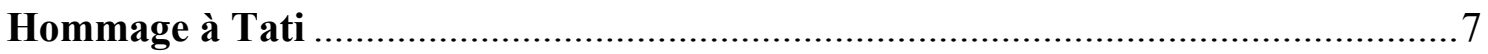

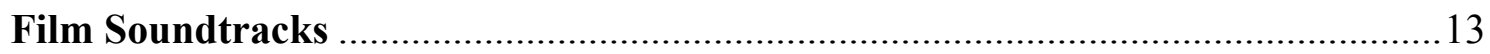

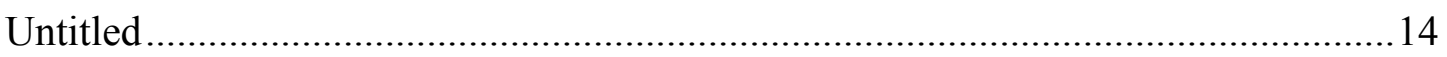

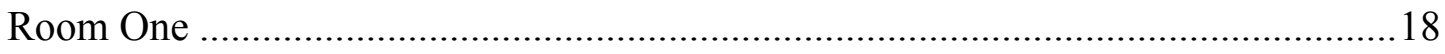

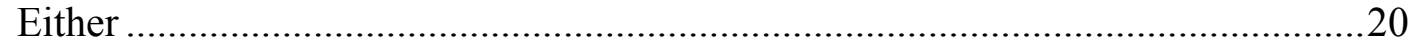

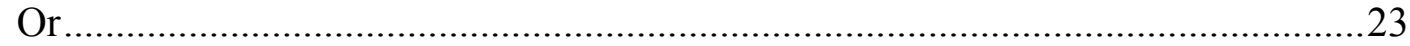

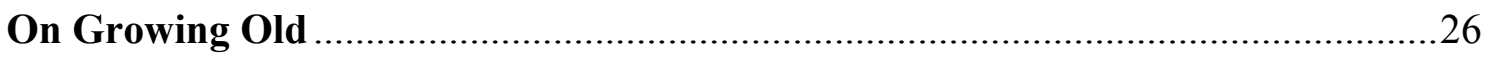

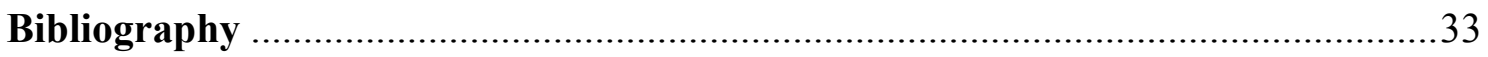

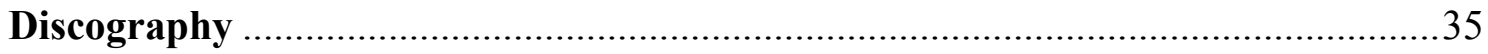

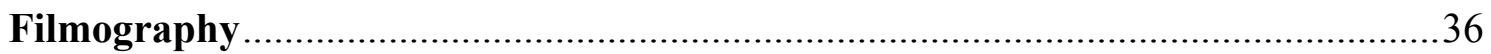

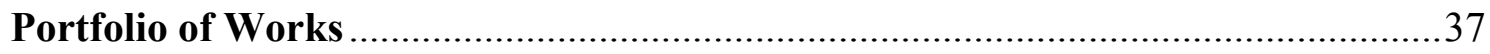

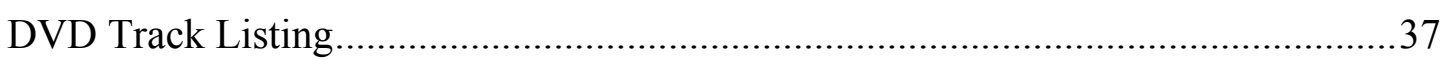




\section{INTRODUCTION}

The following research report is a document intended to support my portfolio of compositions and thus provides the following: firstly, a general overview of the topic described in my abstract; secondly, an introductory overview of my aesthetic concerns, sonic materials and compositional techniques; and thirdly, detailed discussion of each of my compositions in terms of aesthetic concerns, sonic materials and compositional techniques.

\section{Overview of the portfolio}

My portfolio consists of five works that explore 'the cinematic aspects of electroacoustic music' from a range of perspectives. Hommage à Tati is an acousmatic homage to the sonic world of filmmaker Jacques Tati that uses samples taken directly from film. Untitled, Either and Or are soundtracks created for short experimental films using contrasting aesthetic approaches. Finally, On Growing Old is a personal and imagic narrative based on archival cassette recordings.

\section{Overview of the thesis topic}

To begin with it is vital to explain what I mean by 'the cinematic aspects of electroacoustic music'. Firstly, it could be said - and often is said - that electroacoustic music is already cinematic in nature. This is very clear in the following statement from Proy, which is worth quoting at length.

While listening to projected sound we imagine sound images. Our senses become a virtual auditory room, a place where acoustically evoked images arise. The term 'écran sonore' (acoustic screen) by Pierre Schaeffer... describes this virtual auditory room. While listening to sound projection, for instance to radio, the listener $\mathrm{him} /$ herself is the acoustic screen on which sound images are being projected. We listen to sound images created by a composer or a radio producer and form our own personal sound images. ${ }^{1}$

\footnotetext{
${ }^{1}$ Gabriele Proy, 'Sound and sign', in Organised Sound 7(1): 15-19, 2002.
} 
Secondly, as a fixed-media art, electroacoustic music is very similar to film in terms of its techniques and formal vocabulary. As François Bayle points out electroacoustic music is based on 'the possibility of fixing or creating sound, then listening to the trace it has left. This new capability (roughly contemporary with the arrival of photography and cinema) serves our argument in so far as the notion of image constitutes a scale model of appearance. ${ }^{2}$ In a manner similar to film, electroacoustic music also lends itself very well to moving seamlessly between 'real' and 'unreal', due to the availability of a wide range of processing and editing techniques. This in itself makes possible a kind of sonic discourse based on the play-off of recognisable and abstract or abstracted sonic images:

Recognisable source creates expectations about what 'might' come next. Research is beginning to confirm what art has done for centuries: play on the ambiguity between expected certainties and deflected actualities. Sonic art maximises these ambiguities by creating a language that can simultaneously be both lucid and ambiguous. ${ }^{3}$

Thirdly, electroacoustic music, whether acousmatic or multimedia, is inherently imagic, linking it closely to cinematic experience. Indeed, Bayle describes acousmatic sound as a kind of image-of-sound ('i-sound') ${ }^{4}$, while Douglas Lilburn used 'the term "sound image"... in his 1965 acousmatic work, The Return,... thereby circumventing questions of 'music' and focusing on the use of sound as an evocative reflection on a metaphorical text. ${ }^{5}$ Such a way of thinking about electroacoustic music has become very widespread, and allows for a conceptualisation of music in imagic terms both at formal and poetic levels, as is made clear in the following reflection on acousmatic music from Bayle:

Every skill of art and sound technique is invoked to substitute image for object, to generate fictional objects, forging a new compositional writing, a rhetoric, a poetics.

\footnotetext{
${ }^{2}$ François Bayle, 'Image-of-sound, or i-sound: Metaphor/metaform', in Contemporary Music Review, 4: 165-170, 1989.

${ }^{3}$ Paul Rudy, 'Timbral praxis: when a tree falls in the forest is it music?', in Organised Sound 12(1): 5-13, 2007.

${ }_{5}^{4}$ Bayle, 'Image-of-sound, or i-sound: Metaphor/metaform', 165-170.

5 John Young, 'Reflections on sound image design in electroacoustic music', in Organised Sound 12(1): 25-33, 2007.
} 
Thus montage, insertion, extraction, stretching and filtering become method and content, medium and message... ${ }^{6}$

It is in the spirit of the concepts just outlined that I understand 'the cinematic aspects of electroacoustic music', which I have explored both through sound alone (in On Growing Old and Hommage à Tati) and through the linking of sound and image (in Either, Or, and Untitled).

\section{Aesthetic concerns, sonic materials and compositional techniques}

My compositional aesthetic is to approach all sounds, regardless of origin and context, as potential tools and materials in the creative process. In a similar vein, composer Paul Rudy describes electroacoustic music as 'a domain where the cultures of trained educated musicians and popular culture meet through the idea that any sound is music." Such a description suggests a broad creative palette, which I feel links aptly to my own work. I seek out and explore old and new, lo and hi-fi, processed and unprocessed, art music and 'popular' music and incorporate techniques of musique concrète, acousmatic composition, experimental sonic art and popular and dance music (not least of all looping). I am particularly drawn to 'abandoned' sounds, such as samples from LPs long neglected and discarded, and to sounds that convey a sense of age, either sonically (such as the tape recordings in On Growing Old) or referentially (such as the filmic sound samples in Hommage à Tati). Furthermore, it is the creative combination of these sounds that is of particular interest to me. The creation of collages from fragments, new music from old materials, as well as the remixing and recycling/upcycling of sound/music are hardly new concepts; nonetheless to creatively assemble disparate elements in a complementary and appealing form remains a challenge, and indeed one which has faced composers of "sound-based music ${ }^{\circ}$ since the dawn of recorded sound.

In the case of electroacoustic music the composer looks for similarities and/or relationships of sonorities, rhythm, texture, sensation, place, time and cultural reference, in order to both create unity and articulate difference in musically meaningful ways. In

\footnotetext{
${ }^{6}$ Bayle, 'Image-of-sound, or i-sound: Metaphor/metaform', 165-170.

7 Rudy, 'Timbral praxis: when a tree falls in the forest is it music?”, 5-13.

${ }^{8}$ Leigh Landy, Understanding the Art of Sound Organisation, (Cambridge: MIT, 2007), ix.
} 
this sense, my approach to composition could be compared to solving a sonic puzzle, though it should of course be kept in mind that there are many ways in which those puzzle pieces can be arranged and many images that can be created from them. Given such an aesthetic starting point and its diverse materials, my works tend to be developed organically, with much sonic investigation into possible interactions of like and unlike sounds.

At a more familiar level the use of melodic material, often layered to create consonance and dissonance, is a recurring technique in my compositions. I regard this as an important means to evoke an emotional response from listeners. This is a key element of my work whether it is intended to create a sense of fun (Hommage à Tati), melancholy and nostalgia (On Growing Old), tension (Or), or confusion (Either). I make no apologies for adopting such an approach and feel supported in doing so by Salomé Voegelin who decries the conventional 'modernist' approach to electroacoustic music 'which refrains from and even despises any emotional interaction with the material and prefers a formalist, analytical reading instead. Sentimentality and nostalgia are frowned upon and marginalised into the realm of indigenous or feminist practices. Within the art field sentimentality is formalised via the notion of Kitsch, managed within the aesthetic rationality of this identification, and as such drained of any real emotional production'. In my work it is precisely such 'emotional production' that I am interested in, alongside an indispensible focus on the formal aspects of composition.

Sampling is also an important feature of my work, whether 'plundered' from LP or other sources (direct from film in the case of Hommage à Tati) and is used for the specific sonic qualities associated with both the source material and the media which carry it, the latter often used to convey an impression of age (as outlined above), as well as for referential purposes, depending on context. Indeed, samples with such qualities are what Voegelin calls 'sonic memory material', which when 'sampled and collaged together, emphasises the tension between the now and the past in current perception and

\footnotetext{
${ }^{9}$ Salomé Voegelin, 'Sonic Memory Material as Pathetic Trigger', in Organised Sound 11 (1): 13-18, 2006.
} 
draws the listener into its production'. ${ }^{10}$ It should be pointed out that Voegelin is not alone in making such observations. ${ }^{11}$

The use of both audio samples from film and archival recordings in new compositions brings with it context, age and a pre-existing narrative to creatively confront. In the case of the film samples used in Hommage à Tati, a complete audio-visual narrative has already been created in which these sounds originate. They have already been created, manipulated and edited to represent the vision of the filmmaker Jacques Tati. By removing these sounds from their visual context, they take on a new life; nonetheless, the original narrative remains as an impression or trace. This narrative 'imprint' has certainly influenced the approach that I have taken, and the acousmatic work created references both thematic threads and the general spirit of Tati's film. The archival recordings used in On Growing Old exist with an even stronger narrative, that of personal correspondence between family members. It would be difficult to remove this emotive trace when using these recordings, unless one were to completely abstract and dissect the voices purely for their sonic qualities. Needless to say such an approach is contrary to my aesthetic and intent for this piece, so rather than seek to strip these recordings to their formal bones, I have embraced the expressively charged potential of these recordings.

Later in this report I will specifically address the approaches to sampling I have taken in Hommage à Tati, Either and On Growing Old as sampled material forms a large part of the sonic palette of these pieces. However, I note that there is also use of sampling in Untitled and $O r$, albeit to a much lesser extent, and in these pieces the samples are used principally (though not exclusively) for their sonic qualities. For example, Untitled includes use of processed samples of water dripping inside a cave, but these are not used referentially (i.e. the "cave-ness" of the recordings is not apparent in this piece). ${ }^{12}$

\footnotetext{
${ }^{10}$ Voegelin, 'Sonic Memory Material as Pathetic Trigger', 13-18.

${ }^{11}$ See also McKinnon (2006), in which the author explores 'Spectral Memories: the Aesthetics of the Phonographic Recording' and Labelle (2006) who examines 'Phantom Music: radio, memory, and narratives from auditory life.'

${ }^{12}$ Colonial Coachman Holidays Ltd., A Sound Experience in New Zealand (ca.1975: Ambassador Records Sydney) [EP].
} 
Finally, and before embarking on a detailed unpacking of the individual pieces in my portfolio, I will make some brief observations concerning the three soundtracks included. It is clear that film is a complex multimodal medium and it is beyond the scope of this thesis to account for such complexity. The following discussion therefore, only addresses my own creative considerations when approaching the composition of a film soundtrack using the electroacoustic medium.

Though styles of film soundtrack are many and varied, conventional film scoring (orchestral, pitch-based) does still appear to dominate. Though pockets of what could be considered electroacoustic music is regularly found in film soundtracks (mainly as incidental music and sound effects) there does still seem to be a strong association of electroacoustic scores with science fiction, no doubt due in part to the early influence of Louis and Bebe Barron's electronic score for Forbidden Planet ${ }^{13}$ and the subsequent imagic association of electronically produced sounds with 'outer space' and 'other worldliness'. In writing the soundtracks for three short films in this portfolio I hope to demonstrate that electroacoustic music is not only a valid form of film enhancement (in the sense that a conventional soundtrack serves to enhance the filmic experience) but also a particularly effective and creative way to express ideas associated with image and connect the listener/viewer ${ }^{14}$ with these. In approaching the creation of a soundtrack for film the pre-existing narrative is defined by the visual image and the way in which this develops over time. The soundtrack composer can take any number of approaches in response to the film, and the choice of sonic material is limited only by the imagination of the composer and their ability to create a connection between the image and sound. This openness with limits is particularly evident in abstract and experimental films, including those I have created the soundtracks for, and I have sought to use this as an opportunity to move well beyond conventional soundtrack work. I hope this will be made clear through both the soundtracks themselves as well as my analysis of them which is to follow below. Moreover, in my own experience the audience for (acousmatic) electroacoustic music tends to be a limited one and the use of multimedia - whether film, dance, installation art etc - has an important part to play in exposing electroacoustic music to a wider audience.

\footnotetext{
${ }^{13}$ Fred M Wilcox, Forbidden Planet, Metro-Goldwyn-Myer (MGM), 1956.

14 I have chosen to refer to the 'listener/viewer' during this discussion when referring to the whole film experience, in order to emphasise the role that sound and image plays in film.
} 


\section{HOMMAGE À TATI}

In compositionally exploring 'the cinematic aspects of electroacoustic music' it is important to create a purely acousmatic work in order to recognise and explore the ability of sound to evoke image/s in the mind without visual stimulation. The lack of external image in acousmatic music encourages the listener to commit more fully to their aural senses and to carefully dissect sound and draw meaning from it (relative to their own experience), as is made clear in the following statement from composer and theorist of acousmatic music François Bayle:

[The acousmatic is a] pure listening situation, where attention cannot be drawn to or reinforced by a visible (or predictable) instrumental causality. Music conceived only in the form of images-of-sounds (i-sounds) and only perceived at the moment of their projection into space (potentially staged or performed cinematically). ${ }^{15}$

I have chosen to create this acousmatic soundscape using samples taken from a feature film soundtrack in which the sound plays an important role. In this way I am not only exploring the sonic qualities of these sounds but also the new meanings developed when removing them from their relationship with the on-screen image.

Hommage à Tati (hereafter referred to as Hommage) is a sonic exploration of Playtime ${ }^{16}$, a film created by the late French filmmaker Jacques Tati. Playtime loosely follows the character Monsieur Hulot (played by Tati himself), as he tries to harmonise with the intrusion of modern technology into 1960s Paris. In Hommage the listener is invited to wander through this world with Mssr Hulot. Drifting between the lines where reality and the intangible meet, the abstract and inanimate interfere with natural human interaction and betray perception. Machines make music, furniture speaks and objects dance rhythmically, tumbling together with Paris jazz beats. The sound world created is simultaneously chaotic and controlled, babbling and balletic, allowing both exit and entrapment.

\footnotetext{
${ }_{15}^{15}$ Bayle, 'Image-of-sound, or i-sound: Metaphor/metaform', 165-170.

${ }^{16}$ Jacques Tati, Playtime, Madman Entertainment, 1967.
} 
It should be noted that the listener's experience of Hommage will be influenced by their comprehension of the samples in their filmic context, in terms of place, language, time and visual reference - has the listener seen Playtime or any of Tati's films? Have they lived in Paris, lived in the 1960s or a combination of the two? Do they speak French? Yet as I hope the following discussion will make clear, this referential aspect of the film and my use of its soundscape, is only part of a larger set of creative concerns and compositional techniques.

It is Tati's attention to sonic detail that was the inspiration behind writing an acousmatic piece based on soundtrack material taken from the film. Tati's approach to sound in his films is a rare one. He not only creates a visual universe but also an extraordinary sound world. As dialogue is not an important component of most of his films, the use of foley (sound effects), as well as diegetic and non-diegetic sounds, take on an amplified role and for much of the film the foley exists alone as the soundtrack. But these are no ordinary sound effects. Tati is an innovator of sound.

Following the opening credits of Playtime and as the theme music fades out, we begin to hear a rhythmic swishing sound topped by a dulcet whispering as we follow the movements of two nuns walking towards us. Though it is unlikely to be exactly what one might hear if present in the room, the sound perfectly matches the image of the nuns, clad head to toe in white and crowned with sculptural 'angel wing' headpieces that lilt with their measured movement. This is just one of countless examples of the thoughtful sonic interpretations of on-screen image that Tati creates: the recognisable sound effect for the object is often there, but it is enhanced and/or embellished. In terms proposed by film music theorist Michel Chion, this is an instance of added value, 'the expressive and/or informative value with which a sound enriches a given image'. ${ }^{17}$ This is also achieved by attention to spatial placement where the sound of an object is heard at a depth or place that does not correspond with the image, that is, referencing an image/event in the background so as to make it snap to the perceptual foreground for the listener/viewer, while at the same time encouraging the viewer to explore the entire scene in detail.

\footnotetext{
${ }^{17}$ Michel Chion, Audiovision: Sound on Screen, trans. Claudia Gorbman (New York: Columbia University Press, 1994), 130.
} 
Furthermore, in Playtime sounds often do not behave as they are expected to. What we would be unlikely to aurally notice in most films - a zip, chair, typewriter, elevator door for example - become especially interesting and engaging, and create sonic patterns, rhythms and gestures, often with clear musical qualities:

In Playtime, when Hulot sits in the modern chair, it is a visual effect, but the sound's as interesting as the shape of the chair: whoooosh.... the sound will add a new dimension, like putting sound in a painting. ${ }^{18}$

Visually, Playtime can seem very 'normal' - a cityscape with 'modern' buildings, department stores, traffic, people and machines. Its sound world, by contrast, is much less straightforward, and when these sounds are taken out of context and the enhanced foley sounds explored, interesting sonic and compositional possibilities abound.

Hommage is a sound art twist on the popular music 'remix': sampling the rich sonic palette of Playtime, and further enhancing and exploring those sounds using digital signal processing (DSP) and mixing in real-world field recordings. The result is a playful, dancing, dream-like collage of familiar (recognisable) and unfamiliar (morphed, processed) sounds. From the interplay of these sounds emerges a surreal cinematic soundscape that drifts between reality and the intangible, and all points in between. The abstract and inanimate interfere with natural human interaction and subvert perception. Machines and furniture are instruments and objects dance. Like the endearingly bumbling character Hulot, the music often trips over itself, confused and distracted. Yet a clear sense of narrative is never lost, as the music continues to propel itself forward.

Hommage leads the listener through sonic 'scenes', during which they journey through Playtime's airport, department store, office buildings and disintegrating restaurant and navigate traffic, people and machines. The participant is almost constantly moving, floating through worlds, catching snippets of conversation and hints of music and rhythm. Occasionally they are static, stalled by a machine, traffic or a door. The exploration culminates in a kind of sonic circus, a whirling collision of Hommage's

\footnotetext{
${ }^{18}$ Jonathan Rosenbaum, 'Tati’s Democracy: An Interview and Introduction', (1973) $<\mathrm{http}: / /$ www.jonathanrosenbaum.com/?p=15628 $>$ (4 November 2010)
} 
sounds, referencing the film's last scenes of a "climactic "circus" vision of city traffic as an endlessly turning carousel'. ${ }^{19}$ Much of this is conveyed through sonic space, including shifts between imagined/interior and real-world/exterior spaces, creating the kind of 'moving perspective' identified by Barry Truax:

Works with moving perspective rely on spatial transitions, usually simulated or evoked, such as the classic use of doors as transitional spaces in acousmatic music. These works create a sense of travel and narrative..... such journeys needn't occur only in physical space. I would argue that the "outer world" of such pieces may include the inner world of memory, dreams, and metaphor as fluid imagery unconstrained by the acoustics of real spaces; hence the variable perspective offers an unlimited range of approaches. ${ }^{20}$

The listener is transported between scenes both literally, using familiar sonic signals doors, (both real-world samples and those extracted from Playtime - elevators, automatic doors), footsteps and vehicles (buses), and figuratively on waves of rhythm, propelled forward by unfolding gestures and carried aloft by disembodied voices. From the very beginning of Hommage, we are already present in an ambiguous sound world. The idling bus is recognised in its original context but quickly turns into a rhythmic dance, introducing jazz drum beats and other looping patterns. This ambiguity occurs throughout the piece. The listener wanders outside and inside, up and down and through machines, passing people, objects and vehicles, and journeying into the real world, often within a short space of time. For example, at 7'26", a 'real', sonically present elevator opens up into a real world environment, only to close both literally and spatially with the doors of a Playtime elevator at 7'40'. This ambiguity is taken further by using sounds that are processed but still recognisable and yet rendered ambiguous by their placement/context in relation to other sounds. The 'entrapment' from 7'03' - 7' 16 ' is also ambiguous - the sound sample used here is in fact a recurring typewriter motif, but its placement after an exit anticipates an entrance, and the sound is instead imagined

\footnotetext{
${ }^{19}$ Rosenbaum, 'Tati's Democracy: An Interview and Introduction', (4 November 2010)

${ }^{20}$ Barry Truax, "The Analysis of Electroacoustic Music as Soundscape", (2007)

$<$ http://www.sfu.ca/ truax/EMS07.html > (6 Dec 2010)
} 
to be a sticky door handle, trapping the listener in between worlds. ${ }^{21}$ This kind of expectational discourse is typical of much electroacoustic music as identified by Paul Rudy and referenced in my introduction.

Rhythm and movement are also an important feature of Hommage, evidenced by raw (unprocessed) sounds such as footsteps, bus (both for textural oscillation and literal transportation), typewriter, and by particular compositional techniques, which all convey a sense of movement. An example of the latter is the motion created by transformation of sounds, such as at 2'27' where an announcement bell quickly transforms into a repeating clanging church bell sound that drives through to the next section/scene. Similarly, at a rhythmic level repeated machine tones are often used at cadence points, phrase endings and as bridges to new sections, while beginnings of phrases are often impelled by bursts of drum and percussive beats. The DSP Livecut (designed by Smartelectronix) is a live beat-slicer where cuts are organised in blocks to form phrases. Livecut was developed primarily for use in dance music, but true to my aesthetic of combining old with new, I have used it to create abstracted tripping and tumbling rhythms from the 1960s jazz beats of Playtime's soundtrack. It has also been used to create rhythms out of machines and domestic objects, drawing on the already percussive use of these sounds in the Playtime soundtrack.

As well as the exploration of the sonic world of Playtime, Hommage also explores some of the film's themes, such as the relationship between man and machine, the disconnect between people within a community and the chaos, hectic pace and rapid progression of modern society. These thematic references are achieved by the use of processing to play upon meaning in the film, through attention to spatial placement of sounds, layering, texture and rhythm. As an example, at 1'28" we hear a man's gravelly voice, mumbling and muffled by distortion and buzz. In the film, the voice is that of an elderly concierge who is battling with the new intercom system in the foyer of a technologically up-todate office building. In the film the concierge is confused and frustrated with the new technology. In Hommage, this is taken a step further, and he has been taken over by the machine, more specifically his voice is distorted and mechanical. As the listener is

\footnotetext{
${ }^{21}$ Metaphorically the typewriter can also be interpreted as 'entrapment', a mechanical device used in one of the impersonal business environments of Tati's film.
} 
unable to observe the relationship between the concierge and machine, the sounds are exaggerated to make very clear the often troublesome relationship between human beings and technology. In Hommage, voices are only heard through machine intercom, as snippets of conversation abstracted from context ("je demande le quatre cent quarante" at 1'50") or tumbled in delay and rendered into babble. This not only references the way in which technology can disconnect people from each other, an important theme in Playtime, but also reflects Tati's viewpoint regarding dialogue:

My dialogue isn't important; the visual situation is for me number one. The dialogue is background sound as you hear it when you're in the street, in Paris or New York - a brouhaha of voice... ${ }^{22}$

Following from this statement, and as I hope the preceding discussion has made clear, there are very good reasons for working acousmatically with Tati's films: his is a filmic imagination in which sound plays a vital role.

\footnotetext{
${ }^{22}$ Rosenbaum, 'Tati’s Democracy: An Interview and Introduction', (1973).
} 


\section{FILM SOUNDTRACKS}

Composing a soundtrack for film represents the literal interpretation of my abstract's brief to examine 'the cinematic aspects of electroacoustic music'. In order to explore the many different ways of approaching writing for film I have completed three individual soundtracks, two of which are contrasting approaches to the same film, which I will discuss in further detail later.

I looked for particular elements when searching out suitable films for which to create a soundtrack. Firstly, my preference was for a short film by a New Zealand film-maker, ideally without a soundtrack. Furthermore, I searched specifically for an experimental and 'abstract' film, one that provided a form, rather than a conventional narrative. I wanted to be free to explore sonic, interpretive and structural options and not feel bound to a particular interpretation by the narrative. ${ }^{23}$ I was also looking for a certain quality of visual content that connects to my interest in the art, music and cinema of past decades and centuries, particularly when the age of these objects is clearly evident. That is, when it is obvious that such things are aged and have existed in another time than my own, as I am drawn to their worn quality and experience. ${ }^{24}$ The grainy quality of old films appeal for their 'imperfection', and black and white films for the simplicity yet complexity of the colour tones. All of these elements I found in the film Room One, a 1968 black and white experimental film by New Zealand cinematographer Leon Narbey. ${ }^{25}$ Additionally I chose another New Zealand short, Untitled by Lissa Mitchell which, despite its appealing psychedelic complexion and grainy quality was created in the mid 1990s.

\footnotetext{
${ }^{23}$ It should be noted that though both film-makers gave me permission to use their work, neither was thereafter involved in the creation of the soundtracks, further allowing an independent and mostly uninfluenced interpretation of the films.

24 This further relates to my use of sampling, discussed earlier.

${ }^{25}$ Room One is based on one of Narbey's light installations at Elam Art School (Auckland).
} 


\section{UNTITLED - LISSA MITCHELL}

New Zealand, 1995

As indicated in my film introduction, I was initially drawn to Untitled by the experimental category of the piece and its New Zealand production. It was, however, a reference to the late New Zealand artist and filmmaker Len Lye in the descriptive blurb that ultimately persuaded me to view the film. As a great admirer of Lye's work, particularly his mesmerising 'scratch films', (created by drawing and scratching directly onto film reel), I was immediately drawn to Mitchell's own use of painting and scratch techniques, the results of which call to mind 1960s coloured-oil light shows, watercolour palettes, 1980s graffiti art, abstract expressionist painting, cell biology and Lye's Free Radicals. ${ }^{26}$

The soundtrack I have created for Untitled uses a series of sounds that reflect the spectrum of colours and textures of the film, but that also convincingly blend with and morph into each other, often using timbral transformations. For this reason I chose elemental textures - hollow wood-like sounds weave into those derived from plastic, the crackling of which disintegrates into grit and the chaotic dripping of water. More 'cultured' materials are also used, such as layered vocal samples which open into trembling piano and xylophone passages. All these sounds are presented as 'objets sonores', (a term invented by Pierre Schaeffer) not for the purpose of relating them aurally to their original sonic source, but for their sonic qualities, the 'dynamic movements of sounds... sonic morphologies without any reference to the original sonic source of (the) selected sound objects'. ${ }^{27}$

Formally, the film is visually divided into two main sections, framed by introductory and closing sections. Though the two outer parts of the film feature similar scratch images (albeit presented in reverse order), the two middle sections are strikingly different, as I will presently make clear.

\footnotetext{
${ }^{26}$ Len Lye, Free Radicals, (New Plymouth: Len Lye Foundation), 1997.

${ }^{27}$ Proy, 'Sound and sign', 15-19.
} 
Visually, the introduction begins with simple scratch material. The rustling yellowgreen pipes quickly turn into dancing white lines on a black surface. These images jerk and jiggle, rattling together only to shake away again. The sound in this early part of the film closely parallels this vigorous visual activity - phrases are uneven, syncopated and with accents just as likely to fall in the middle of a phrase as at the beginning. Changes in pitch and density mirror the altering positions of the images. At 0 ' 40 " the dancing lines abruptly disappear, and the film opens into a watercolour wash and an altered sound world, establishing the first main section.

One of my initial reactions when considering a compositional response to Untitled was that whilst watching the film 'naked' (without a soundtrack), this first section, at almost four and a half minutes - well over half the film - seemed long and drawn out, with similar images punctuated only occasionally by flashes of new material. However, far from this being a negative characteristic, I could see the clear potential for a soundtrack to enhance and explore the details of colour, shape, and texture, and to pull, twist and drive this material towards the startling Mesmer/rising sun image at 5'02'.

Upon visually exploring the first section more comprehensively, one observes not only the fluctuating tones of colour but also their ever-changing density and shape, from vertical brushstrokes, scratches, dashes and drops to bubbles of colour that spread into an ocean, saturating the screen. Often these different forms are layered together. For this reason my approach to setting this section was first to determine patterns, pulse and form from which to mould a structure. Careful shaping of this section with sound was vital - creating variance in speed, intensity and rhythm and drawing out the characteristics of the images. By creating a sense of forward motion through sonic shape and texture, I could create a linear structure where one would otherwise not exist.

However, due to the chaotic nature of the images and rapidity of changes, it was difficult and undesirable to map every twist and turn. I instead identified a number of points of visual reference (distinct changes in colour, texture, ends and beginnings of visual 'phrases') for which I assigned a specific sound(s) or change(s) in timbral quality. In between these structural marker points I allowed some of the microstructure to be developed aleatorically, by using DSPs that randomise material by pitch, grain size and rate within a sample buffer (e.g. GRM Tools' Freeze and Soundhack's Bubble Delay). 
Further sonic turbulence was created by taking two samples of the same sound, slightly processing one, (such as through slight pitch variation or rolling off of high or low frequencies), then layering the two just slightly askew. Such layering of like and unlike sounds can draw particular imagic qualities to the foreground. For example, from 1'38" as dark hues invade the screen the layering of low bubbling drums creates aural depth and urgent undulations, enhancing the dark and shadowy nature of the image - the dark hues cloaking the light.

Looped material often appears in the background, giving some stability to an otherwise often chaotic soundscape. An example of this is evident in a short section beginning around 2'40". Here the gritty sound material in the foreground starts to disintegrate and at 3'00" a dark wash covers the entire screen for a few seconds, creating a brief moment of stasis. However, the pitched drip loop that is heard quietly in the background continues to drive the film forward to the burst of colour and sound that opens out at 3'03'.

Occasionally, small punches of layered vocal, violin and trumpet appear, increasing in length as the piece progresses. These samples not only act as bridges between the percussive material and piano/xylophone, but also foreshadow later vocal material, particularly the transition into and beginning of the second section.

Though sonically anticipated by the quiet layered vocals associated with it, the Mesmer/rising sun image at 5'02" that begins the second section is still an unfamiliar sight and quite unexpected for the viewer. It almost appears as though the projector has malfunctioned and is running a different film. I used predominantly vocal material at this point for a few reasons. Firstly, there was a clear need for a distinct aural change from the prior material to reflect the change in the film. Secondly, the vocal 'oooo' suitably mirrors the directional nature of the Mesmer/sun, spiralling inwards towards a dark tunnel. Thirdly the Mesmer/sun image combines with the only 'real world' footage within the film - a clapper board, a wall and a hand. In this way, vocal material creates a connection between the listener/viewer and the brief opening of the film into 'reality'.

Unlike the previous section, where the visual material is somewhat similar and it is the sound that creates the shape, the second section has segments of distinctively different 
visual material that quickly advance, taking the music with them. Here there is a rapid progression to the climax, which is driven by both the sound and the film working in tandem. A flurry of words leads up to the climax, and I have creatively attended to these words primarily as new and distinct images, and to a lesser extent, to their meanings. Like the Mesmer/sun image, these new images capture our visual attention as they are unfamiliar within the film, but structured in acutely recognisable shapes (letters). The words propel the image forward to the climax and are not heard in literal utterance, but gently emphasised by textural sounds, sibilance and whispering. The underlying sound layer is akin to warning bells, and though a nod to the negative connotations of the words, it is used primarily as a climax, growing in tension as the bells mimic the flurry of letters, stumbling over one another culminating in an intense ringing in the ears. The tension releases at 6'30" to the familiar dancing black and white material from the introduction, the hollow rattling preceding the image just slightly, in order to anticipate the abrupt change in visual material. This short ending section is treated sonically in much the same way as the beginning until it fades out both spectrally and dynamically. 


\section{ROOM ONE - Leon Narbey}

New Zealand, 1968

Leon Narbey's Room One provided me with an opportunity to extend my exploration in writing for film, as will become clear in the discussion that follows. At 3'40" the film is the perfect length to complete two contrasting soundtracks, using different sonic material, and different aesthetic approaches. In so doing, I wished to explore the potential for the soundtrack to transform and manipulate the reaction and experience of the listener/viewer even as they are confronting the same visual material. This relates to film music theorist Michel Chion's advocacy of an exercise he calls 'forced marriage' where contrasting musical accompaniments are added to film sequences and 'played over the images in an aleatory manner'. This 'marriage' of diverse sound and image inevitably creates moments of relation between the two, and these correspondences and the audiovisual experience will vary depending on the listener/viewer's own perspective. In this way Chion shows the crucial role that music plays in the reception of a film:

Changing music over the same image dramatically illustrates the phenomena of added value, synchresis, sound-image association and so-forth... We begin to see the image in all its potential signification and expression. ${ }^{28}$

The narrative style created in Narbey's Room One also lends itself to contrasting soundtrack approaches. Though the narrative appears to be linear, this is disrupted by the film editing, which creates abrupt shifts and cuts, thus confusing the viewer's sense of linearity.

Because these rooms, these installations, were temporary structures, I wished to record them somehow.... However due to the complication of lighting... we began to alter the environment and it became a film experience... It no longer became the reality of documentating [sic] these installations so much as making a rhythmical structure to indicate some meaning in terms of rhythms, alternating colour flashes,

\footnotetext{
${ }^{28}$ Chion, Audiovision: Sound on Screen, 188-89.
} 
and integrating these with the musical soundtrack. ${ }^{29}$

This narrative style can be compared to that of Dziga Vertov's Man with a Movie Camera ${ }^{30}$ in which many varied scenes were filmed without an initial sense of how they would fit together. These included shots of daily life, details of machines, landscapes and a few staged moments. The shots were catalogued in a database, then cut and edited together by a separate editor, thereby forming a collection of images somewhere between a narrative and database film. This image 'collage' with its contrasting subjects and range of cinematic techniques lends itself to varied sonic interpretations. It is therefore unsurprising that there have been a substantial number of soundtracks created for Man With a Movie Camera in equally varying styles and approaches including orchestral, electroacoustic (Pierre Henry), jazz/electronica (Cinematic Orchestra), fusion, and live improvisational performances.

Similarly, Room One's abstract linear narrative and highly rhythmical structure offers a receptive canvas on which to paint contrasting soundtracks and as such I have created two examples for this portfolio. I have named them Either and $O r$, in order to avoid any suggestion of hierarchy (as conveyed by numbers or letters). The differences between the soundtracks might be understood as follows. Either takes a more linear and expressive approach, exploring the narrative potential of the film (albeit in an unusual way, as I will explain), while $O r$ is more abstract, in that it concentrates on the sonic and formal relationships between sound and film.

${ }^{29}$ Leon Narbey, 'Focus on Leon Narbey, Alternative Cinema', (1981).

$<$ http://www.filmarchive.org.nz/the-catalogue/media/room-one-f339916> (12 Nov 2010).

NB. Although this quote references a musical soundtrack, the copy of Room One that I reviewed at the NZ Film Archive did not appear with one.

${ }^{30}$ Dziga Vertov, Man with a Movie Camera, Amkino Corporation (US), 1929. 


\section{EITHER}

My approach to Either is that of a loose narrative. The soundtrack for Either begins approximately five seconds before the audience sees a visual image. Not only does the ear precede the eye, but when the soundtrack begins, a distinctive introductory melody is heard, establishing sound as the leading element. As sight is activated, the image seems to respond to the sound. The lights turn on and off, in reply to the music, but just slightly adrift, lagging at times behind the music. At 0'16", with the first appearance of 'the Man', we now sense that it is he who is turning the light on and off in reaction to the music. Shortly, when we tilt away from the bulb to the wall, it is the cylinder that shifts in shadow, hesitantly, lurching in time to the new sliced-up looping melodies. The rhythmic interplay created between the sound and film during this early section is akin to mickey-mousing (the close synchronisation of sound and image), but is used as an expectational framework within which a more complex rhythmic language is created: the rhythm pushes and pulls with the film, at times anticipatory, synchronised, clumsy, syncopated. The exaggerated accordion waver creates its own micro-rhythm.

In this interpretation of the film, the anthropomorphised room ('the Room') is in control, in the sense that the room itself appears to have agency. Accordingly, 'the Room' is given a dominant sonic identity and appears to manipulate the objects within itself - the box, cylinder, ladder, handle and 'the Man'. The man and the room are loosely characterised and represented by contrary sonic palettes. This anthropomorphic approach is reflected in the following discussion, in which I directly link the soundtrack and the psychological experience which both the room and the man might be experiencing.

'The Room' is announced by the original accordion trio samples - the timbre is bold and bright, the progressions harmonically simple, playful, confident and dominant. The initial material densely fills the stereo space and creates spatial saturation, inducing a feeling of claustrophobia, which continues throughout the film, and is thus representative of the enclosed space and the entrapment it enacts.

'The Man's' uncertain personality begins to creep in from 1'18'. After the taunting and sinister single accordion notes at 1'41", we are exposed to his emotional interior with 
the new violin sample that quickly deteriorates into discord. By the time we see him climbing the ladder at 2'13" the soundtrack has opened up and enveloped his subconscious, which is warped and confused. The sonic image here is very much in the foreground. It could be said that 'the Man' is dissonance consisting of polyrhythmic layers of tonal and textural discord. Gradual layering in the soundtrack increases tension as the film progresses. We hear 'the Man's' voice peek through during this section (actual vocal samples). He faces the handle, perhaps imagining escape, but 'the Room' is in control, issuing a harsh sonic warning (created using time and grain-stretched inharmonic notes) and so he descends, defeated. Thus we later look down on the room, which is playing with the man like a puppet, throwing him from place to place, laughing and teasing until finally he disappears.

Structurally, the last moments of the film soundtrack echo the original accordion melody, heard in an altered form. Here I use a technique to create sonic disorder amongst melodies by layering one pitch-shifted region upon the original, (often by only a semitone or less) slightly ahead or behind in metre, creating dissonance and a feeling of 'sighing' and winding down. 'The Room' is represented in this way as a sad, tired and petulant child who has lost their toy (in this case, 'the Man').

\section{The use of sampling in Either}

Either makes extensive use of an Austrian accordion trio, Die 3 Echten Wiener [The 3 True Viennese], as recorded on LP in $1976 .^{31}$ This recording features the trio's interpretations of traditional Austrian folksongs, originally written many years before. The re-use of this discarded and unplayed record in an electroacoustic soundtrack for an experimental film, crosses boundaries of era, style and cultural background and places them in juxtaposition. In particular, and as mentioned above, I am drawn to the abandonment; to the sound of the vinyl record itself, the sonic properties of the accordion and the potential to mould old and sentimental into something new. Above all, however, the use of these particular samples is intended to evoke a general sense of agedness and of the past, as outlined in my introduction.

\footnotetext{
${ }^{31}$ Die 3 Echten Wiener, 'Wann Am Kalvariberg', 'Da Drunt Im Stoanagrabn', 'Sag Hast Ka Bett Fur Mich' and 'Die Besten Freund' Auf Dera Welt', on Servus Spezi (1976: STEREO 9105 034) [LP].
} 
It is quite likely that upon hearing the accordion sample, some receivers

(listeners/viewers) may be cognitively transported to France, particularly in the first few seconds before the film begins. Nonetheless, there is a strong tradition of accordion music throughout Europe, not least of all in Austria. It is also possible that a receiver may recognise the folk songs, despite the fact that they have been 'remixed', sliced into parts, changed in pitch and stretched in time. It is my anticipation however, that due to the disconnection of the film from any particular place, and the abstract nature of the images, that once the visual begins to unfold, any cultural or personal association will quickly become at the very least, confused, and the samples will subsequently become recontextualised and reframed within the film. In this sense my approach also demonstrates, to an extent, the importance of Pierre Schaeffer's ecouté reduite (reduced listening) to the interpretation of electroacoustic music that makes use of recognisable sound sources. That is, in listening to such music one must to an extent listen to sonic materials as sound, abstracting them from their context, rather than understanding them as pointers to specific sources and cultural reference points.

Overall then, in using this record, my intent is not only recontextualisation - drawing new meanings from sampled materials - but also revitalisation, that is, bringing new life to sounds forgotten, abandoned or even unheard. 
Or offers an alternative interpretation and perspective of Room One for the receiver. The main focus of my approach here is the relationship between sound and image, specifically sonic and visual texture, timbre and atmosphere. In a sense it is an imagining of what the room might sound like if one were to 'play' it, within the rhythm defined by the film. In discussing Either, I presented a linear description in keeping with the film's structure. In the case of $O r$, which plays upon the visual rhythm of the film and its disjunctures, I will discuss the specific techniques I have used to explore this interpretation in terms of structure, sonic palette and spatial perspective and the interconnections between them.

As I am more concerned with detail and specific points of audio-visual connection in $\mathrm{Or}$, I have allowed the images and editing of the original film to define the macro structure. The result of this is that the soundtrack explores the possibilities opened up by what Michel Chion calls synchresis, 'The spontaneous and irresistible mental fusion, completely free of any logic, that happens between a sound and a visual when these occur at exactly the same time'. ${ }^{32}$ This technique allows for the creation of a bold matching of sound and image, while overt mickey-mousing is avoided by microstructrual manipulation of sonic tempo and texture, dynamics and points of climax/false climax, as I will make clear in the ensuing discussion.

The film can be split into four main sections preceded by an introduction. The first section begins at 0 '26" with an opening up of the visual space by panning; the shadowed reintroduction of the man begins the second section at 1'39", followed by an intensification of images and light leading to a short climax explosion at 2'11"; the third section is created with a slowing down of editing cuts from 2'30" and the last 'burst' section attacks from 3'08" to the end.

Within this visual structure the pulse and speed is manoeuvred by sections of alternating aural tempo. A long focus on the close-up cylinder image from 0 ' 47 " initiates a playful rhythmic interaction between the rapidly changing shadows and jerky percussive

\footnotetext{
${ }^{32}$ Chion, Audiovision: Sound on Screen, xviii.
} 
rattling in the soundtrack. These moments of audio-visual rhythm are interspersed with slower, more open sections and wide panning on-screen is often followed by slow or static sound, whether it appears in the back or foreground (for example, sideways panning to the cylinder from 0'35" - 0'40”). On a micro level, movements of objects, flickers and flashes of light and editing changes are mirrored by sound, as are small details. At 0'20" - 0'22”, for example, pitched material moves in rhythm to the tiny points of reflected light on the dark bulb. As in Either a sound phrase will sometimes continue where the on-screen movement has finished, enhancing the previous filmic action by allowing the ear to further absorb an idea from which the eye has already moved on.

Or's sonic palette is deliberately limited (though there are many micro-variances within these confines, such as those created through time-stretching), which is an aural analogue of the limited visual landscape: the film takes place in one location - a stark black and white room with cold hard surfaces. Accordingly, there are four main categories of sound:

- metallic/industrial,

- unpitched percussive, representing object, surface, movement and rhythm

- atmospheric mist

- fragments of melody which loosely represent the human figure (man)

This uninviting setting with its harsh lighting, cold metal and concrete surfaces, sharp edges and flat faces, is expressed sonically by pitch, texture and timbre: metallic sounds are abrasive, clattering, screeching or crunchy, heard alone or layered with brittle, jagged, shaking or fluttering percussive sounds. The dark shadows are a wailing wind, slow and swollen.

The objects in the room - box, cylinder, ladder, light, pipes - often seem as if they are being hit or scraped to create the discordant soundscape as the sound interacts with the image. Both percussive and pitched sounds have been deliberately fractured by using various distortion plug-ins (e.g. Digidesign's $L o-F i$ ), including bit-rate and depth distortion. 
Changes in sonic material are often abrupt and gestural, echoing the rapid editing and changes in light and shadow. A clattering foreground gesture will fall off, to be replaced by a static or slow-moving sound cloud in the background, for example those accompanying the close-up of the handle at 2'24" (fading pitches and rattling attack), release into a reverb-laden whine that shadows the man atop the wall at 2'27'. This opening into spatial depth recurs throughout the film, as does the layering of low, mid and high frequencies, often formed as murky atmospheric sound cloud in the background, percussive attacks in the mid-ground and high frequency, and high energy sound in the foreground, which is spectrally clear and present. 


\section{ON GROWING OLD}

One of the most frequently explored ideas in cinema is that of a personal story, which can take the form of fact or fiction, or a combination of both. It is one of the most effective ways of 'reaching' an audience and of evoking an emotional response. Similarly, through the combination of spoken word material, programmatic music, sonic associations and indicators, a strong sense of a narrative, story-like experience can be created without the use of visual stimuli, on a par with that encountered by the audience of a film. In this aspect of the aural-cinematic experience, the final piece in my portfolio takes a personal narrative approach through the use of archival recordings made by my family in the early 1980 s.

In 1982 my immediate family moved from England to New Zealand leaving our small, but close-knit extended family behind. For the first three years of our new life in New Zealand, we exchanged 'tape letters' with my maternal grandparents. These letters included 'fly-on-the-wall' recordings, discussion of everyday events, stories and poems, musical interludes and messages of love. The last recording made was the only one recorded by my grandmother by herself after the death of my grandfather in 1985, and since then the recordings had been stored away for many years, and largely forgotten.

On Growing Old (hereafter referred to as $O G O$ ) uses samples taken directly from these archival cassette tapes, supported by new recordings made by me to create a personal narrative exploring both the relationship between my grandparents and me and, more broadly, the experience of growing old. Though we often think of technology as disconnecting us from each other (an idea which arises in Hommage), in the case of my family's tape letter correspondence, technology allowed us to remain connected, to maintain intimacy through hearing each other's voices, it enabled my grandparents an aural experience of their grandchildren growing up, and allowed the sharing of day-today happenings that may not have been discussed in a telephone conversation.

Overall, the use of archival material in $O G O$ is approached quite differently to the use of samples in the other pieces in this portfolio. Here the emphasis is very much on the referential and emotional qualities of the recordings, something entirely appropriate to the narrative nature of $O G O$. In retrieving these archival recordings and exploring their 
contents I not only discovered an important family time capsule but, more personally, a new awareness of my relationship with my grandparents.

The first tape in the collection was made on the day my family departed England. This tape features a recording of my grandmother reading the first stanza of the poem $O n$ Growing Old by English poet John Masefield:

Be with me, Beauty, for the fire is dying;

My dog and I are old, too old for roving.

Man, whose young passion sets the spindrift flying,

Is soon too lame to march, too cold for loving.

I take the book and gather to the fire,

Turning old yellow leaves; minute by minute

The clock ticks to my heart. A withered wire,

Moves a thin ghost of music in the spinet.

I cannot sail your seas, I cannot wander

Your cornland, nor your hill-land, nor your valleys

Ever again, nor share the battle yonder

Where the young knight the broken squadron rallies.

Only stay quiet while my mind remembers

The beauty of fire from the beauty of embers.

I found this recorded segment to be particularly engaging and revealing as there seemed to be a genuine connection between my grandmother and her recitation, though they are not her own. Her voice sounds tired and sad, with an understanding of and empathy for the subject of the poem. I have used the reading of this poem as a platform from which to explore the themes of age, distance, time and memory which are key to both the poem and my piece, particularly through the use of archival recordings.

The use of archival recordings in any creative art form evokes a sense of past and agedness: 'Memory, according to Bergson, is the intersection of mind and matter'. ${ }^{33} \mathrm{In}$ On Growing Old the medium of the cassette tape itself serves to establish this

${ }^{33}$ Voegelin, 'Sonic Memory Material as Pathetic Trigger', 13-18. 
intersection. The sonic signals of tape hiss and clicks are understood by the contemporary listener and place the recordings in the past, more specifically to a time when portable cassette tape recording devices were available to and used by the general public. Similarly, the voice is also a recognisable sonic indicator of age. The sonorities of my grandmother's voice, which is the first to be heard, are recognisable as the voice of someone elderly, a comprehension intensified by the subject matter of the poem she is reading and her intonation, which conveys a sense of weariness.

The varying sonic qualities of the tape samples also correspond to the age and distance of the speaker. The recordings of my grandparents have been made at a distance from a device with a low quality microphone and a greater amount of tape hiss is heard, interfering with their speech and in some instances clouding particular words. This is most noticeable during the section in which my grandfather relays his dream - the tape hiss here is a sonic smog that cloaks his words. The struggle to hear what he is saying echoes both the physical distance between us, and his ailing health at the time. In contrast, the recordings of my mother and I are much clearer and easily understood, representing our relative youth and closeness to the perspective of the listener, whose experience of the piece is guided by point of view.

The tape hiss material itself can also be interpreted metaphorically by way of a sonic connection to the sound of the ocean and surging waves, or to other natural sounds (wind, for example), representing the ebb and flow of life. It is also used structurally, to link sections and create stasis (it is, after all, a kind of static), the unchanging nature of the sound allowing contemplation whilst maintaining a connection between the listener and the narrative (i.e. not introducing complete silence). Tape clicks are also used as structural devices, the literal turning on and off of the tape to open and close sections e.g. 2'26", and for their rhythmical nature and emphasis e.g. 10'40”'.

In a similar manner, the ticking of a clock is a recognisable and well-used sonic symbol indicating the passing of time, or more specifically the future or past. The clock image features in the text of Masefield's poem and at 8'53" I have used my grandmother's own reading of the word 'ticks' to create an abstract onomatopoeic clock, subsequently continued by my own voice (9'16"), which I regard as a passing of time between generations. 
Recorded material also acts as a memory charge, creating an emotional immediacy and strong sense of nostalgia/melancholy. This is made clear in the following statement from John Young:

Portable recording equipment has.... [allowed] the recording process to be regarded as a means of reflection on experience, a kind of memory-tool... the phenomenon (or the magic?) of familiar sounds recorded and played back is common-place and understood at a fundamental level as a process with expressive potential. $^{34}$

This quality is intensified where the recorded material is speech, which creates an immediate connection between the listener and the audio. In $O G O$, for example, laughter is a recurring motif - though my grandfather died when I was only five years old, I still retain vivid memories of his laugh and his voice, as well as the smell of pipe tobacco, of which he was fond. These archival recordings are rich with memories: I can remember and perceive far more clearly who my grandparents were by listening to their voices than by looking at photographs.

In $O G O$ there are clear differences between material evoking the present (clear, sonically present recordings of my voice), that which evokes the past (tape recordings) and that which conveys a 'forever' quality through use of repetition ("be with me"). A notable example of the blurring of time and memory occurs through the telling of a story from 5'43", at which point my grandfather begins to describe a dream he has had about his grandchildren. His description of the situation that led to the dream is presented in its original form but as he starts to describe the dream itself, the listener moves sonically inside it, hearing the voices of my sister and I in a swirling surreal montage. This section not only represents my grandfather's dream but also the memory of him, and his passing.

\footnotetext{
${ }^{34}$ John Young, 'Reflections on sound image design in electroacoustic music', in Organised Sound 12(1): $25-33,2007$.
} 


\section{Structure and form}

$O G O$ has an episodic structure: the poem (split into three sections), and tape letter content are interspersed with melodic material and small, melodic snippets of the poem text (in particular the phrase "be with me beauty"). A brief overview of the main sections follows which will then be discussed in more detail. The piece begins slowly and with textural simplicity, opening up into more complex layered sections after a few minutes; the main body of the narrative alternates between rhythmic sections with forward motion and more static and contemplative stretches of material. In between these are moments of melodic material which is used for both purposes: the repeated piano motif serves to impel the narrative forward, while layered vocal material allows the material to ebb and flow within a static section. The last few minutes of the piece establishes tension, then release, and finally a lingering reverie.

Melodic material appears throughout the piece in the form of a recurring piano motif, layered vocal harmonies without recognisable words, low grounded vocal swells and single phrase refrains ("be with me", "fire is dying"). The melodies are often layered over each other, creating quiet dissonances, and evoking emotions including uncertainty, anticipation, nostalgia, and loss. The melodic material is used for bridging sections, creation of atmosphere through dissonance, grounding, creating space, forward motion and periods of stasis that allow the listener to consider the previous material. For example the faraway child singing from 7'26" (me), followed by a low vocal tone allows contemplation of the previous dream sequence and anticipates the new section at 8 '21'”.

$O G O$ begins with a section of tape hiss and the introduction of a main 'character' (my grandmother) reading the first section of Masefield's poem. The atmosphere and tone, evoking weariness and age, is also set through the use of a repeated piano motif and a murmur of vocal material underneath the text. The second section at 2'26” is sonically simpler and introduces the next two 'characters' - myself as a small child and my mother. The following section beginning at 3'34" is a montage of voices in which the last 'character', my grandfather is introduced. He is the focus of the fourth main section from 5'43" during which he relays a dream. At 8'21" the middle part of the poem is expressed in a more rhythmical form, after which the penultimate section (featuring the 
final lines of the poem) opens up into a contemplative section referencing loss and regret. The final section from 12 ' $44^{\prime \prime}$ is not an ending so much as a drifting into time and space.

A sense of time within the overall structure is created by utilising repetition and memory-replay. These take the form of vocal refrains and repetition of spoken word text from both from the poem and tape letters - and occur in different ways within the piece. Some recur regularly throughout ("be with me, beauty"); some are repeated rapidly within one particular section only ("old yellow leaves", 1'32"; "round and round the garden", 6’41”); some repeated refrains appear only occasionally, scattered through the piece ("traces of it still in my voice"); and some take the short form of an echo by the use of delay. Both laughter (discussed earlier) and my grandfather's creaking chair are also recurring motifs. A particularly persuasive use of repetition occurs from 11'09 where a questioning 'hello' is offered into the void by my voice at four different ages.

Further perceptions of time are created by the use of what might be called 'direct memory', for example the conversation between my mother and me discussing our trip to the park (at 2'28') and specific reference to days and dates during the subsequent section from 3'57'. Here a bundle of correspondence dates are overlapped in an oftused technique to represent time passing. The alternation of rhythmic sections impelling forward motion and moments of relative stasis also references the passing of time - the ebb and flow of life events - thus reinforcing the general emphasis on temporality in the piece.

The ending of the piece has been deliberately sculpted to feel incomplete - in this way I present the preceding sections as a 'conversation' between me and my grandparents, now and in the past, and therefore in the future; indicating that though they have passed on the relationship continues just as it did when we moved to the other side of the world.

Overall then, this is a reflective piece. The use of long sections, often minimally 'adulterated' provides a chance for the listener to absorb the poem and the sense of mood and atmosphere, rather than be pulled along by the narrative. The quality of my grandparents' voices is rich with depth and sonic complexity. However, rather than pulling the voices apart to explore and exploit/manipulate the sound, I have instead 
chosen to allow the sounds to 'speak' for themselves, in keeping with my approach to the archival recordings as pieces of personal history, memory and emotion. 


\section{BIBLIOGRAPHY}

\section{Books}

Chion, Michel. Audiovision: Sound on Screen, trans. Claudia Gorbman. New York: Columbia University Press, 1994.

Landy, Leigh. Understanding the Art of Sound Organisation. Cambridge: MIT, 2007.

\section{Articles}

Bayle, François. 'Image-of-sound, or i-sound: Metaphor/metaform'. Contemporary Music Review 4 (1989), 165-170.

Labelle, Brandon. 'Phantom Music: radio memory and narratives from auditory life'. Organised Sound 11/1 (2006), 19-25.

Proy, Gabriele. 'Sound and sign'. Organised Sound 7/1 (2002), 15-19.

Rudy, Paul. 'Timbral praxis: when a tree falls in the forest is it music?'. Organised Sound 12/1 (2007), 5-13.

Voegelin, Salomé. 'Sonic Memory Material as Pathetic Trigger'. Organised Sound 11/1 (2006), 13-18.

Young, John. 'Reflections on sound image design in electroacoustic music'. Organised Sound 12/1 (2007), 25-33.

\section{Poetry}

Masefield, John. 'On Growing Old'. (1919), 1-14. 


\section{Internet Materials}

McKinnon, Dugal. 'Spectral Memories: the Aesthetics of the Phonographic Recording'. (2006) < http://www.hz-journal.org/n12/mckinnon.html> 10 Nov 2010.

Narbey, Leon. 'Focus on Leon Narbey, Alternative Cinema'. (1981)

<www.filmarchive.org.nz/the-catalogue/media/room-one-f39916>12 Nov 2010.

Rosenbaum, Jonathan \& Tati, Jacques. 'Tati's Democracy: An Interview and Introduction'. $(1973)<\mathrm{http}: / / w w w . j o n a t h a n r o s e n b a u m . c o m / ? p=15628>$. 4 Nov 2010.

Truax, Barry. 'The Analysis of Electroacoustic Music as Soundscape'. (2007)

$<$ http://www.sfu.ca/ truax/EMS07.html >. 6 Dec 2010. 


\section{DISCOGRAPHY}

Colonial Coachman Holidays Ltd. (A Newmans Subsidiary). A Sound Experience in New Zealand. Ambassador Records Sydney, ca.1975. [EP]

The Curro Amaya Dancers. 'Soleares' and 'Sevillana'. Flamenco Candido! PYE RECORDS MAL620, 1967. [LP]

Die 3 Echten Wiener. 'Wann Am Kalvariberg', 'Da Drunt Im Stoanagrabn', 'Sag Hast Ka Bett Fur Mich' and 'Die Besten Freund' Auf Dera Welt'. Servus Spezi. 9105 034, 1976. [LP].

Henry, Pierre. L'homme à la Camera. Mantra Records MANTRA092, 1994. [CD]

Janssen, Geir (Biosphere) and Martinsen, Per (Mental Overdrive). 'Soundtrack for Man With a Movie Camera' Substrata 2 (Disc 2). Touch Records, 2001. [CD]

Pachacamac. 'Totoras, sikuerada' and 'El Castillo, vals venezolano'. Music of the Incas. EMI AVRS 11722, 1975.[LP]

Simpson/Taylor Family. Tape Correspondence, 1982-1985. [CASSETTE]

Various. 'Sawing Wood', 'Pistol Shots, Random Fire', 'Pinball Machine' and ‘Teletypes'. 133 Authentic Sound Effects. ELEKTRA EKL-7313/7314, ca 1960s. [LP] 


\section{FILMOGRAPHY}

Cinematic Orchestra. Man with a Movie Camera. Ninja Tunes, 2003.

Lye, Len. Free Radicals. Len Lye Foundation, 1997.

Mitchell, Lissa. Untitled. Self-produced, 1994.

Narbey, Leon. Room One. Self-produced, 1968.

Tati, Jacques. Playtime, Madman Entertainment, 1967.

Vertov, Dziga. Man with a Movie Camera. Amkino Corporation (US), 1929.

Wilcox, Fred M. Forbidden Planet. Metro-Goldwyn-Myer (MGM), 1956. 


\section{Acousmatic}

Hommage à Tati (2009)

On Growing Old (2010)

\section{Film Soundtracks}

Untitled (2010)

Either (2010)

Or (2010)

1. Hommage à Tati (wav.)

2. Untitled (mov.)

3. Either (mov.)

4. Or (mov.)

5. On Growing Old (wav.) 
Availability and Deposit of Thesis Form

\begin{tabular}{|c|c|}
\hline Author's Name & Sarah Elizabeth Taylor \\
\hline Thesis Title & The Cinematic Aspects of Electroacoustic Music \\
\hline Degree Name & MMus \\
\hline Discipline & Composition \\
\hline School & New Zealand School of Music \\
\hline Supervisor(s) & Dugal McKinnon \\
\hline Year & 2010 \\
\hline Keywords (3) & ELECTROACOUSTIC MUSIC. FILM MUSIC. SOUNDTRACKS. \\
\hline \multicolumn{2}{|l|}{ Research Code } \\
\hline $\begin{array}{l}\text { Availability } \\
\text { Statement }\end{array}$ & $\begin{array}{l}\text { I hereby consent to the above thesis being consulted, borrowed, copied or } \\
\text { reproduced in accordance with the provisions of the Library Regulations from } \\
\text { time to time made by the Academic Board. }\end{array}$ \\
\hline \multicolumn{2}{|l|}{ Signature } \\
\hline Date & $\begin{array}{l}8 \\
\end{array}$ \\
\hline Deposit Statements & $\begin{array}{l}\text { I agree to Victoria University of Wellington and Massey University having the } \\
\text { non-exclusive right to archive digitally and make publicly accessible this thesis. } \\
\text { Creator/Contributor(s) } \\
\text { I am the sole creator of this work as a whole and can archive digitally and make } \\
\text { accessible the work. I own the intellectual property rights inherent in the work as } \\
\text { a whole. I have explicitly acknowledged in the work any significant contribution } \\
\text { made to the work by others and the sources that I have used. } \\
\text { Third Party Content } \\
\text { I declare that if this work is archived digitally and made accessible, it will not be } \\
\text { in breach of any agreement with a third party that has or is entitled to publish this } \\
\text { work. } \\
\text { Verification } \\
\text { I am supplying the digital file that is a direct equivalent of the work which is } \\
\text { described and referred to in this declaration. } \\
\text { Preservation and Distribution } \\
\text { I agree to Victoria University of Wellington and Massey University having the } \\
\text { right to keep this work in any file format and copy the thesis and transfer it to any } \\
\text { file format for the purposes of proservation and distribution. }\end{array}$ \\
\hline Signature & trat fon L \\
\hline Date & $\left(\int_{8|l| l} 11^{13}\right.$ \\
\hline
\end{tabular}




\section{STATEMENT OF AUTHORSHIP \\ BY MASTER'S CANDIDATE}

Except where specific reference is made in the main text of the thesis, this thesis contains no material extracted in whole or in part from a thesis, dissertation, or research paper presented by me for another degree or diploma.

No other person's work (published or unpublished) has been used without due acknowledgment in the main text of the thesis.

This thesis has not been submitted for the award of any other degree or diploma in any other tertiary institution.

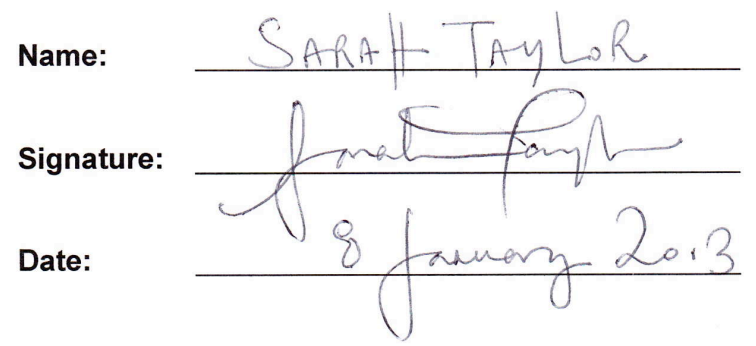

PLEASE RETURN TO THE FHSS STUDENT \& ACADEMIC SERVICES OFFICE MURPHY 411 